\title{
Community health services and risk of readmission in public psychiatric hospitals of Belo Horizonte, Brazil, 2005-2011
}

\author{
Cobertura de serviços extra-hospitalares e risco de reinternação nos hospitais \\ psiquiátricos públicos de Belo Horizonte, 2005 a 2011
}

Fernando Madalena Volpe, Isabela Pinto Braga, Eliane Mussel da Silva

\begin{abstract}
Introduction: The readmission phenomenon in psychiatry not only reflects the severity and chronicity of the underlying disorders, but also indicates the quality of mental healthcare. In the context of the Brazilian mental healthcare reform, no study has included the availability of outpatient care among the potential determinants for psychiatric readmission.

Objective: To correlate the availability of community healthcare resources at the place of residence with the risk of psychiatric readmission.

Methods: All admission records from 2005 to 2011 in the two public psychiatric hospitals of Belo Horizonte were included $(n=19,723)$. Variables related to patients and characteristics of hospitalization were collected, and indicators of community healthcare coverage were calculated for each place of residence yearly. The outcome of interest was early ( $<7$ days), mediumterm (8-30 days) and late (31-365 days) readmissions. The analysis was based on Cox regressions.

Results: The coverage of basic health units and of psychiatrists was associated with lower readmission risks. Coverage of specialized centers for psychosocial attention (Centros de Atenção Psicossocial [CAPS]) and psychologists did not show any protective effects. Young, male patients and those residing outside the capital had greater risk of early readmission. Compared to other psychotic disorders, mood disorders and neurotic disorders were seen as protective factors for readmission.

Conclusion: Regionalized attention offered by the CAPS did not result in reduced readmission risks.
\end{abstract}

Keywords: Hospital readmission, community mental health services, risk factors.

\section{Resumo}

Introdução: O fenômeno da reinternação psiquiátrica reflete não apenas a gravidade e cronicidade da doença de base, mas também a qualidade dos serviços de saúde. Ainda não há estudos incluindo a disponibilidade de recursos assistenciais extra-hospitalares como preditor da readmissão psiquiátrica, no contexto da reforma da assistência à saúde mental brasileira.

Objetivo: Correlacionar a disponibilidade de recursos de assistência extra-hospitalar das localidades de residência com o risco de readmissão psiquiátrica.

Métodos: Foram analisados todos os registros de internações ocorridas de 2005 a 2011 nos dois hospitais psiquiátricos públicos de Belo Horizonte $(n=19.723)$. Foram coletadas variáveis relativas aos pacientes e às características da internação, e calculados indicadores de cobertura em saúde extra-hospitalar para cada localidade de residência e ano. O desfecho de interesse foi a reinternação precoce (<7 dias), de médio prazo (8-30 dias) e tardia (31-365 dias). A análise se deu por regressões de Cox.

Resultados: A cobertura de unidades básicas de saúde e de psiquiatras se associou a menores riscos de reinternação. A cobertura de Centros de Atenção Psicossocial (CAPS) e de psicólogos não apresentou efeitos protetores. Pacientes jovens e do sexo masculino, assim como os residentes fora da capital, tiveram risco maior de reinternação precoce. Em comparação com outros transtornos psicóticos, os transtornos de humor e os transtornos neuróticos se apresentaram como fatores protetores para a reinternação.

Conclusão: A atenção regionalizada oferecida pelos CAPS não resultou em riscos reduzidos de reinternação.

Descritores: Readmissão do paciente, serviços comunitários de saúde mental, fatores de risco. 


\section{Introduction}

Readmission to the psychiatric hospital is a common event, ranging from 14 to $56 \%$, depending on the timeframe and type of hospital assessed.1-8 Severe psychiatric disorders often display a chronic and recurrent clinical course. The readmission phenomenon not only reflects the severity and chronicity of the underlying disorder, but also indicates the quality of mental healthcare. ${ }^{9-11}$ On one hand, this depends on the efficiency of the inpatient care in adequately stabilizing the patient before discharge, allowing reinsertion in the community. On the other hand, in order to avoid readmissions, adequate postdischarge care should also be available, involving a healthcare team that is capable of preventing recidivism and recurrence.

In Brazil, appreciation of public outpatient services increased substantially in the last four decades. ${ }^{12,13}$ The previous model was hospital-centered and outpatient clinics were scarce. ${ }^{12-14}$ A great impulse for shifting this paradigm occurred when a federal regulation was sanctioned, in 2001 (Federal Law 10.216/2001). ${ }^{15}$ Aiming to protect the rights of mental health patients, it redirected the model of care. The current key strategy involves the progressive reduction of psychiatric beds and the expansion of the so-called "substitutive services" -mostly outpatient facilities that encompass, among other resources, specialized centers for psychosocial attention (Centros de Atenção Psicossocial [CAPS]), and the assessment of patients by family health teams supervised by specialized advisors of a mental health team (Núcleos de Assistência Psicossocial [NAPS]). ${ }^{16}$

The efficiency of this system, however, has not been formally evaluated. To our knowledge, there are many international, 2,4,17-26 but only one Brazilian study ${ }^{8}$ assessing the risk factors for psychiatric readmission. The focus is usually on individual clinical and social features of inpatients, or at most, on the characteristics of the hospitals. Despite its relevance in the context of the Brazilian mental healthcare reform, no study has included the availability of outpatient care among the potential determinants for readmission. If the assumption that outpatient facilities simply step in for psychiatric beds is valid, then increasing the availability of outpatient resources should reduce the risk of readmission.

The present study challenges this hypothesis by investigating the determinants of readmission in the two public psychiatric hospitals of Belo Horizonte, state of Minas Gerais, Brazil, focusing on the availability of outpatient care resources where patients reside.

\section{Methods}

This observational study adopted a retrospective cohort design. It was conducted in the two public psychiatric hospitals of the metropolitan region of Belo Horizonte, state of Minas Gerais, Brazil, namely, Hospital Galba Velloso (HGV) and Instituto Raul Soares (IRS). Both hospitals are administrated by Fundação Hospitalar do Estado de Minas Gerais (FHEMIG). During the study period, those two facilities encompassed all the psychiatric hospital beds available for adults on the Brazilian Unified Health System (Sistema Único de Saúde [SUS]).

In July 2008, HGV had 137 beds (87 in male wards and 50 in female wards); IRS had 60 beds in male wards, 44 in female wards, and 12 switchable beds, totalizing 116 beds. Both hospitals received patients from all the state of Minas Gerais and had an open psychiatric emergency room during the study period.

Database records of all admissions to HGV and IRS taking place from January 2005 to December 2011 were included in this study. The variables collected from this source were: record number, age upon admission (in years), gender, diagnosis at discharge (according to the International Classification of Diseases, 10th revision [ICD-10]), dates of admission and discharge, and place of residence. Place of residence was divided as follows: a) patients living in Belo Horizonte were grouped according to the large eight catchment areas into which the capital is divided; b) those living in other cities of the metropolitan region of Belo Horizonte were grouped by city. Admissions of patients residing outside the metropolitan region were not included.

The coverage of outpatient psychiatric services and resources was based on the Brazilian National Registry of Healthcare Facilities (Cadastro Nacional de Estabelecimentos de Saúde [CNES]), available online. For each catchment area of Belo Horizonte, or for each city of the metropolitan region, the number of basic health units, CAPS, as well as the number of psychiatrists and psychologists were obtained. Coverage rates per 100,000 population were calculated yearly. Population counts were estimated using the censuses of the Brazilian Institute of Geography and Statistics (IBGE) undertaken in 2000 and 2010, by performing linear growth projections and interpolations.

Length of stay of each admission (in days) was calculated by subtracting the date of discharge from the date of admission (thus the last day of each admission was not computed).

The outcome variable was readmission. This was defined as a new admission of the same patient, regardless of diagnosis, within periods of 1-7 days 
(early readmissions), 8-30 days (medium-term readmissions), and 31-365 days (late readmissions), subsequent to the preceding admission. Thus, one same patient with multiple readmissions over 365 days would be considered more than once. The individualization of patients was based on the equivalence of three variables: record number, date of birth and gender.

When conducting the analyses of risk factors for readmission, only hospitalizations that occurred after January 2006 were included, and the admissions of 2005 were considered as a reference for defining readmissions in the following year. By doing this, all observations had the same risk of being a case of readmission.

\section{Statistical analyses}

After performing a descriptive analysis of the study variables, the factors associated with risk of readmission were analyzed by separate Cox proportional hazards regressions for each type of readmission (early, mediumterm, or late). The outcome variable was the interval until readmission, and the predictive models included simultaneously all the variables of potential interest: patient characteristics, length of stay of the previous admission, and indicators of availability of outpatient healthcare resources of the catchment area/city of origin. Data were right censored when no readmission occurred in each period of study. Considering the exploratory nature of this study, statistical significance was considered when $\mathrm{p}<0.05$.

\section{Results}

In the period of study (2005-2011), a total of 19,723 admissions were computed: 11,800 for HGV (59.9\%) and 7,923 for IRS. Detailed features of those admissions are presented in Table 1 . Admissions included patients residing in Belo Horizonte (46.4\%) and in 33 cities of the metropolitan region. When we focused on readmissions occurred between 2006 and 2011, 1,115 (5.7\%) were early readmissions ( $<7$ days), 1,160 (5.9\%) were medium-term readmissions (8-30 days), and 3,178 (18.9\%) were late readmissions (31-365 days after the previous discharge). Table 2 shows the readmission rates for each hospital during the study period.

Table 1 - Profile of admissions to the two public psychiatric hospitals of Belo Horizonte, Brazil (Hospital Galba Velloso and Instituto Raul Soares), 2005-2011

\begin{tabular}{|c|c|c|c|c|c|c|c|c|c|c|}
\hline \multirow[b]{2}{*}{ Variables } & \multicolumn{2}{|c|}{$\begin{array}{c}\text { Non- } \\
\text { readmissions }\end{array}$} & \multicolumn{2}{|c|}{$\begin{array}{c}\text { Early } \\
\text { readmissions } \\
(<7 \text { days }) \\
\end{array}$} & \multicolumn{2}{|c|}{$\begin{array}{l}\text { Medium-term } \\
\text { readmissions } \\
(8-30 \text { days })\end{array}$} & \multicolumn{2}{|c|}{$\begin{array}{c}\text { Late } \\
\text { readmissions } \\
(31-365 \text { days }) \\
\end{array}$} & \multicolumn{2}{|c|}{ All readmissions } \\
\hline & $\mathbf{n}$ & $\%$ & $\mathbf{n}$ & $\%$ & $\mathbf{n}$ & $\%$ & $\mathbf{n}$ & $\%$ & $\mathbf{n}$ & $\%$ \\
\hline Male gender & 7,224 & 63.2 & 850 & 73.5 & 892 & 67.6 & 3,837 & 65.9 & 12,803 & 64.9 \\
\hline Age (years), mean (SD) & \multicolumn{2}{|c|}{$38.3(12.0)$} & \multicolumn{2}{|c|}{$33.2(10.9)$} & \multicolumn{2}{|c|}{$35.2(10.9)$} & \multicolumn{2}{|c|}{$37.0(11.0)$} & \multicolumn{2}{|c|}{$37.4(11.7)$} \\
\hline \multicolumn{11}{|l|}{ Diagnoses } \\
\hline F00-09 & 392 & 3.4 & 51 & 4.4 & 30 & 2.3 & 132 & 2.3 & 605 & 3.1 \\
\hline F10-19 & 3,836 & 33.6 & 377 & 32.6 & 520 & 39.4 & 2,288 & 39.4 & 7,021 & 35.7 \\
\hline F20-29 & 4,196 & 36.8 & 434 & 37.6 & 464 & 35.2 & 2.111 & 36.3 & 7,205 & 36.6 \\
\hline F30-39 & 2,046 & 17.9 & 126 & 10.9 & 214 & 16.2 & 865 & 14.9 & 3,251 & 16.5 \\
\hline F40-49 & 382 & 3.4 & 9 & 0.8 & 22 & 1.7 & 133 & 2.3 & 546 & 2.8 \\
\hline Other & 574 & 4.9 & 160 & 13.7 & 69 & 5.2 & 291 & 4.9 & 1,095 & 5.4 \\
\hline Length of stay (days), mean (SD) & \multicolumn{2}{|c|}{$13.0(23.9)$} & \multicolumn{2}{|c|}{$10.5(19.4)$} & \multicolumn{2}{|c|}{$13.0(16.7)$} & \multicolumn{2}{|c|}{$14.4(23.0)$} & \multicolumn{2}{|c|}{$13.7(33.7)$} \\
\hline \multicolumn{11}{|l|}{ Hospital } \\
\hline Hospital Galba Velloso & 6,952 & 60.8 & 824 & 78.2 & 763 & 57.8 & 3,261 & 56.0 & 11,800 & 59.8 \\
\hline Instituto Raul Soares & 4,474 & 39.2 & 333 & 28.8 & 557 & 42.2 & 2,559 & 44.0 & 7,923 & 40.2 \\
\hline
\end{tabular}

$\mathrm{SD}=$ standard deviation.

* F00-09 = organic mental disorders; F10-19 = substance abuse/dependence-related disorders; F20-29 = schizophrenia and other psychotic disorders; F30-39

= mood disorders; F40-49 = neurotic disorders.

Results in bold font indicate significant differences compared to non-readmissions $(p<0.05)$. 


\section{Availability of outpatient healthcare and risk of readmission}

A description of the indicators of availability of outpatient mental health professionals and mental health services in the catchment areas of Belo Horizonte and cities of the metropolitan region (2006 and 2011) is presented in Table 3.
The availability of basic health units in the catchment area/city of origin was an independent protective factor for early, medium-term, and late readmissions. The availability of psychiatrists in the catchment area/city of origin was also a protective factor against medium-term and late readmissions, but not against early readmissions ( $<7$ days). So, the higher the number of basic health units

Table 2 - Early, medium-term, and late readmission rates in the two public psychiatric hospitals of Belo Horizonte, Brazil, $2006-2011$

\begin{tabular}{|c|c|c|c|c|c|c|c|c|c|}
\hline \multirow[b]{2}{*}{ Year } & \multicolumn{3}{|c|}{$\begin{array}{l}\text { Early readmission rates } \\
\text { ( }<7 \text { days })\end{array}$} & \multicolumn{3}{|c|}{$\begin{array}{c}\text { Medium-term readmission rates } \\
\text { (8-30 days) }\end{array}$} & \multicolumn{3}{|c|}{$\begin{array}{c}\text { Late readmission rates } \\
(31-365 \text { days })\end{array}$} \\
\hline & HGV & IRS & Total & HGV & IRS & Total & HGV & IRS & Total \\
\hline 2006 & 7.2 & 4.3 & 6.1 & 6.7 & 6.3 & 6.6 & 19.2 & 23.1 & 20.7 \\
\hline 2007 & 6.3 & 3.8 & 5.4 & 6.2 & 6.7 & 6.4 & 20.3 & 22.6 & 21.2 \\
\hline 2008 & 7.9 & 4.3 & 6.4 & 5.3 & 6.5 & 5.8 & 19.3 & 20.3 & 19.6 \\
\hline 2009 & 9.1 & 4 & 7.1 & 5.5 & 5.4 & 5.5 & 18.7 & 21 & 19.6 \\
\hline 2010 & 7.5 & 3.5 & 5.8 & 4.5 & 6 & 5.1 & 20 & 21.2 & 20.5 \\
\hline 2011 & 7.1 & 3.9 & 5.6 & 6.6 & 6.1 & 6.4 & 19.4 & 21.5 & 20.4 \\
\hline Total & 7.5 & 4 & 6.1 & 5.8 & 6.1 & 5.9 & 19.5 & 21.6 & 20.3 \\
\hline
\end{tabular}

Data presented in \%.

HGV = Hospital Galba Velloso; IRS = Instituto Raul Soares.

Table 3 - Indicators of availability of outpatient mental healthcare, according to catchment area/city, in Belo Horizonte and metropolitan region, 2006 and 2011

\begin{tabular}{|c|c|c|c|c|c|c|c|c|c|c|}
\hline \multirow[b]{2}{*}{ Region/city } & \multirow{2}{*}{$\begin{array}{l}\text { Number of } \\
\text { admissions }\end{array}$} & \multirow[b]{2}{*}{$\%$} & \multicolumn{4}{|c|}{$\begin{array}{c}\text { Basic health } \\
\text { units* }\end{array}$} & \multicolumn{2}{|c|}{ Psychiatrists* } & \multicolumn{2}{|c|}{ Psychologists* } \\
\hline & & & 2006 & 2011 & 2006 & 2011 & 2006 & 2011 & 2006 & 2011 \\
\hline \multicolumn{11}{|l|}{ Belo Horizonte } \\
\hline Barreiro & 969 & 10.6 & 0.73 & 0.35 & 7.68 & 7.41 & 4.02 & 3.88 & 10.98 & 12.71 \\
\hline Centro-Sul & 1134 & 12.4 & 0.00 & 0.00 & 4.87 & 4.77 & 5.24 & 2.93 & 14.98 & 9.90 \\
\hline Leste & 1712 & 18.7 & 0.79 & 0.40 & 5.17 & 6.02 & 4.77 & 4.42 & 11.52 & 12.04 \\
\hline Nordeste & 1200 & 13.1 & 0.35 & 0.34 & 7.06 & 7.54 & 2.47 & 2.40 & 8.12 & 10.28 \\
\hline Noroeste & 1309 & 14.3 & 0.60 & 0.60 & 6.88 & 5.74 & 3.59 & 1.51 & 10.47 & 6.04 \\
\hline Norte & 478 & 5.2 & 0.00 & 0.00 & 7.83 & 9.36 & 2.45 & 2.34 & 7.34 & 8.89 \\
\hline Oeste & 1442 & 15.7 & 0.36 & 0.35 & 6.12 & 5.93 & 3.60 & 3.14 & 8.27 & 9.42 \\
\hline Pampulha & 441 & 4.8 & 0.60 & 1.06 & 4.79 & 7.40 & 5.39 & 4.23 & 9.58 & 11.62 \\
\hline Venda Nova & 480 & 5.2 & 0.39 & 0.38 & 5.89 & 6.47 & 1.18 & 1.52 & 3.93 & 6.09 \\
\hline \multicolumn{11}{|c|}{ Metropolitan region } \\
\hline Baldim & 13 & 0.1 & 0.00 & 0.00 & 12.46 & 12.36 & 0.00 & 0.00 & 0.00 & 12.36 \\
\hline Betim & 269 & 2.5 & 0.87 & 1.05 & 7.51 & 8.66 & 3.76 & 2.36 & 12.72 & 18.11 \\
\hline Brumadinho & 32 & 0.3 & 3.26 & 2.92 & 32.60 & 37.93 & 3.26 & 2.92 & 13.04 & 35.01 \\
\hline Caeté & 125 & 1.2 & 0.00 & 0.00 & 25.81 & 26.89 & 5.16 & 2.44 & 12.91 & 17.11 \\
\hline Capim Branco & 19 & 0.2 & 0.00 & 0.00 & 130.36 & 123.36 & 11.85 & 11.21 & 82.96 & 78.50 \\
\hline Confins & 10 & 0.1 & 0.00 & 0.00 & 201.42 & 184.02 & 18.31 & 16.73 & 128.17 & 117.10 \\
\hline Contagem & 4197 & 39.8 & 0.35 & 0.66 & 20.56 & 19.31 & 1.57 & 0.83 & 12.72 & 13.37 \\
\hline Esmeraldas & 219 & 2.1 & 1.84 & 1.66 & 5.52 & 3.32 & 0.00 & 1.66 & 7.36 & 14.93 \\
\hline Florestal & 10 & 0.1 & 0.00 & 0.00 & 64.82 & 60.61 & 16.21 & 15.15 & 48.62 & 30.30 \\
\hline Ibirité & 836 & 7.9 & 0.68 & 1.88 & 17.65 & 15.63 & 2.04 & 2.50 & 10.86 & 18.75 \\
\hline Igarapé & 42 & 0.4 & 0.00 & 2.87 & 6.58 & 20.09 & 0.00 & 0.00 & 16.45 & 8.61 \\
\hline
\end{tabular}


and psychiatrists per 100,000 population, the higher the intervals until readmission and, thus, the lower the risks of readmission (Figure 1 ).

Unexpectedly, the availability of CAPS and of psychologists in the catchment area/city of origin were negatively and significantly associated to the intervals until readmission, especially for late readmissions. So, the higher the number of CAPS or psychologists per 100,000 population, the higher the risks of readmission (Figure 1 ).

Table $\mathbf{3}$ (cont.)

\begin{tabular}{|c|c|c|c|c|c|c|c|c|c|c|}
\hline \multirow[b]{2}{*}{ Region/city } & \multirow{2}{*}{$\begin{array}{l}\text { Number of } \\
\text { admissions }\end{array}$} & \multirow[b]{2}{*}{$\%$} & \multicolumn{4}{|c|}{$\begin{array}{c}\text { Basic health } \\
\text { units* }\end{array}$} & \multicolumn{2}{|c|}{ Psychiatrists* } & \multicolumn{2}{|c|}{ Psychologists* } \\
\hline & & & 2006 & 2011 & 2006 & 2011 & 2006 & 2011 & 2006 & 2011 \\
\hline Itaguara & 19 & 0.2 & 0.00 & 0.00 & 58.88 & 56.58 & 0.00 & 0.00 & 0.00 & 0.00 \\
\hline Itatiaiuçu & 10 & 0.1 & 0.00 & 0.00 & 64.57 & 50.36 & 0.00 & 0.00 & 0.00 & 10.07 \\
\hline Jaboticatubas & 60 & 0.6 & 0.00 & 0.00 & 25.78 & 23.35 & 0.00 & 0.00 & 12.89 & 11.67 \\
\hline Juatuba & 41 & 0.4 & 0.00 & 0.00 & 40.80 & 0.00 & 0.00 & 0.00 & 15.30 & 27.02 \\
\hline Lagoa Santa & 169 & 1.6 & 2.17 & 3.76 & 19.57 & 30.09 & 4.35 & 1.88 & 23.92 & 24.45 \\
\hline Mario Campos & 31 & 0.3 & 0.00 & 0.00 & 25.00 & 15.04 & 0.00 & 0.00 & 8.33 & 15.04 \\
\hline Mateus Leme & 66 & 0.6 & 0.00 & 0.00 & 38.19 & 43.08 & 0.00 & 0.00 & 26.74 & 14.36 \\
\hline Matozinhos & 41 & 0.4 & 3.10 & 2.93 & 37.22 & 32.26 & 0.00 & 5.87 & 12.41 & 20.53 \\
\hline Nova Lima & 255 & 2.4 & 0.00 & 1.22 & 23.11 & 24.49 & 2.72 & 4.90 & 12.24 & 20.81 \\
\hline Nova União & 21 & 0.2 & 0.00 & 0.00 & 36.38 & 17.99 & 0.00 & 0.00 & 18.19 & 17.99 \\
\hline Pedro Leopoldo & 101 & 1.0 & 1.77 & 1.70 & 28.28 & 25.46 & 0.00 & 3.39 & 21.21 & 27.16 \\
\hline Raposos & 67 & 0.6 & 0.00 & 0.00 & 0.00 & 0.00 & 0.00 & 6.52 & 13.45 & 26.07 \\
\hline Ribeirão das Neves & 1459 & 13.8 & 1.09 & 1.01 & 23.35 & 21.79 & 1.09 & 2.35 & 14.60 & 18.78 \\
\hline Rio Acima & 25 & 0.2 & 0.00 & 0.00 & 23.68 & 11.00 & 0.00 & 0.00 & 23.68 & 22.00 \\
\hline Rio Manso & 12 & 0.1 & 0.00 & 0.00 & 40.07 & 37.74 & 0.00 & 0.00 & 20.03 & 18.87 \\
\hline Sabará & 816 & 7.7 & 0.82 & 0.79 & 11.54 & 11.84 & 1.65 & 2.37 & 9.89 & 12.63 \\
\hline Santa Luzia & 929 & 9.8 & 0.00 & 0.98 & 26.00 & 11.80 & 0.00 & 1.97 & 0.00 & 16.71 \\
\hline São Joaquim de Bicas & 11 & 0.1 & 8.47 & 7.73 & 101.62 & 92.77 & 16.94 & 15.46 & 143.96 & 131.43 \\
\hline São José da Lapa & 28 & 0.3 & 11.33 & 10.00 & 135.95 & 119.98 & 22.66 & 20.00 & 192.60 & 169.97 \\
\hline Sarzedo & 68 & 0.6 & 0.00 & 0.00 & 13.62 & 23.24 & 0.00 & 0.00 & 4.54 & 19.37 \\
\hline Taquaraçu de Minas & 8 & 0.1 & 0.00 & 0.00 & 1.57 & 52.71 & 0.00 & 0.00 & 0.79 & 0.00 \\
\hline Vespasiano & 549 & 5.2 & 0.00 & 1.89 & 14.13 & 14.18 & 1.09 & 0.95 & 5.44 & 9.46 \\
\hline
\end{tabular}

CAPS $=$ specialized centers for psychosocial attention.

* Rates per 100,000 population.

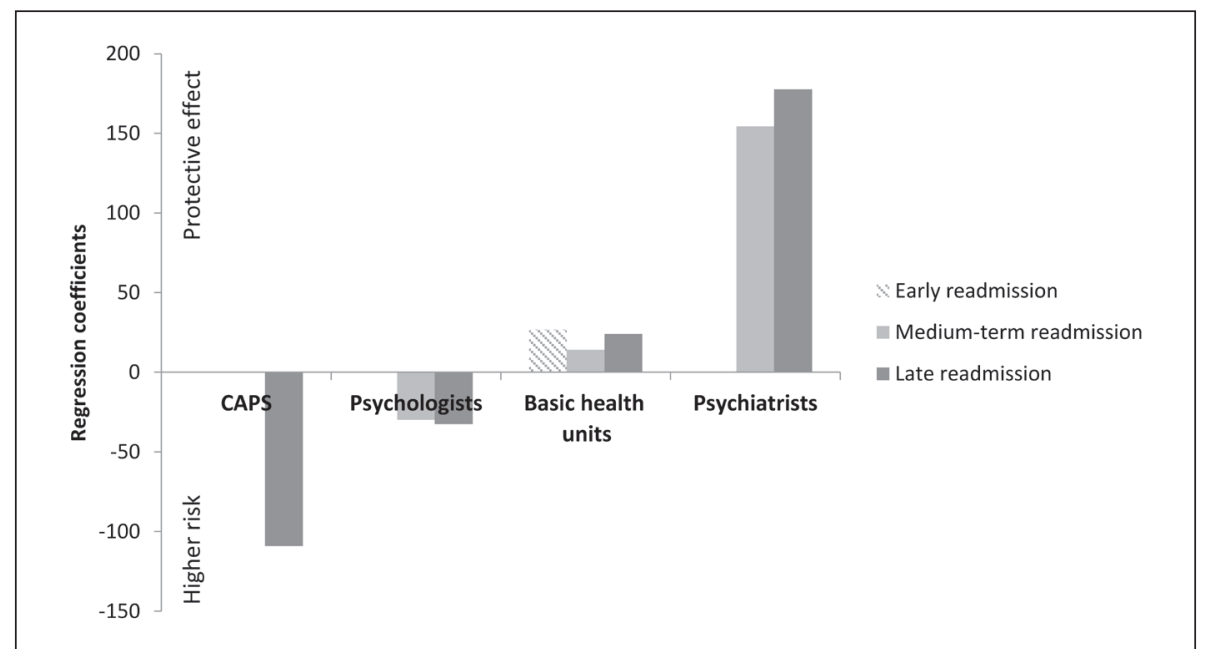

Figure 1 - Independent relative effects of the availability of outpatient resources on risk of readmission. Non-significant results were omitted. Negative coefficients indicate higher risk of readmission, and positive coefficients indicate protective effects. Coefficients are proportional to $\log _{\mathrm{e}}$ (time to readmission). CAPS = Centros de Atenção Psicossocial. 


\section{Patient characteristics and risk of readmission}

Young age was an independent risk factor for early, medium-term, and late readmission. Being a male and residing outside the capital were both risk factors for early readmission.

The most prevalent diagnostic group in this sample was schizophrenia and other psychotic disorders (ICD10 F20-F29), accounting for $36.6 \%$ of all admissions. All other diagnoses were compared to that group.

The risk of a late readmission was relatively higher for cases of substance abuse/dependence (F10-F19) and of organic mental disorders (F00-F09). Diagnoses of mood disorders (F30-F39) and of neurotic, stressrelated and somatoform disorders (F40-F49) were, in general, protective factors for readmission (Table 4).

\section{Features of index admissions and risk of readmission}

Higher lengths of stay were associated with lower risks of early readmission but higher risks of late readmission. Comparing to being admitted to HGV, patients admitted to IRS showed a higher risk of late readmission, but a lower risk of early readmission.

\section{Discussion}

Despite the considerable efforts in pursuit of progressive dehospitalization in the context of the mental healthcare reform in Minas Gerais, readmission rates are still relevant (32\%). The rates observed in the present study are within those reported for other services in Brazil and in other countries (14-56\%). ${ }^{1-8}$ However, the dynamics of the persistent phenomenon of readmissions deserves further reflections.

Almost two-thirds of all readmissions occurred after 30 days of discharge. Possible reasons for late readmissions include: a) non-adherence to post-discharge therapeutic recommendations (i.e., non-attendance to scheduled consultations, stopping medication against advice); b) obstacles in effectively accessing outpatient post-discharge care (i.e., strikes or other reasons for the absenteeism of health professionals, unavailability of the prescribed medication, difficulties in scheduling return visits); c) natural periodicity of the underlying disease (i.e., mood episodes); and d) chronicity and lack of therapeutic response, especially in cases of substance abuse/dependence, leading to disease progression that culminates with readmission.

Table 4 - Cox regression results analyzing risk factors for early, medium-term, and late readmissions in Hospital Galba Velloso and Instituto Raul Soares, 2005-2011 $(n=19,723)$

\begin{tabular}{|c|c|c|c|c|c|c|}
\hline \multirow[b]{2}{*}{ Predictor variables } & \multicolumn{2}{|c|}{$\begin{array}{c}\text { Early readmissions } \\
\text { (<7 days) }\end{array}$} & \multicolumn{2}{|c|}{$\begin{array}{c}\text { Medium-term } \\
\text { readmissions ( } 8-30 \text { days) }\end{array}$} & \multicolumn{2}{|c|}{$\begin{array}{l}\text { Late readmissions } \\
\text { (31-365 days) }\end{array}$} \\
\hline & Coefficient & $\mathbf{p}$ & Coefficient & $\mathbf{p}$ & Coefficient & $\mathbf{p}$ \\
\hline CAPS/100,000 population & 95.44 & 0.147 & -70.86 & 0.224 & -109.07 & $<0.001$ \\
\hline Basic health units $/ 100,000$ population & 26.72 & $<0.001$ & 13.98 & 0.009 & 23.99 & $<0.001$ \\
\hline Psychiatrists/100,000 population & 13.73 & 0.702 & 154.32 & $<0.001$ & 177.59 & $<0.001$ \\
\hline Psychologists/100,000 population & -12.47 & 0.121 & -29.93 & $<0.001$ & -32.67 & $<0.001$ \\
\hline Age & 39.20 & $<0.001$ & 22.81 & $<0.001$ & 5.62 & $<0.001$ \\
\hline Male gender & -327.34 & $<0.001$ & -61.74 & 0.371 & -1.89 & 0.947 \\
\hline \multicolumn{7}{|l|}{ Diagnosis group } \\
\hline F00-09 & -544.51 & 0.001 & 108.21 & 0.597 & 259.72 & 0.002 \\
\hline F10-19 & 19.36 & 0.813 & -298.90 & $<0.001$ & -225.32 & $<0.001$ \\
\hline F30-39 & 266.99 & 0.019 & -97.32 & 0.295 & 103.60 & 0.009 \\
\hline $\mathrm{F} 40-49$ & 1675.46 & $<0.001$ & 581.81 & 0.014 & 248.76 & 0.003 \\
\hline Outros & -870.29 & $<0.001$ & -65.48 & 0.644 & -42.09 & 0.487 \\
\hline Length of stay & 9.55 & $<0.001$ & 0.10 & 0.944 & -2.19 & $<0.001$ \\
\hline Being admitted to Instituto Raul Soares & 332.01 & $<0.001$ & -150.90 & 0.017 & -201.36 & $<0.001$ \\
\hline Residing in the metropolitan region* & -837.42 & $<0.001$ & 66.04 & 0.581 & 6746 & 0.187 \\
\hline
\end{tabular}

Distribution: logistic; Log-likelihood = -12743.101 (0-7 days), -15095.044 (8-30 days), and -56745.535 (31-365 days).

F00-09 = organic mental disorders; F10-19 = substance abuse/dependence-related disorders; F30-39 = mood disorders; F40-49 = neurotic disorders

In this analyses, F20-29 (schizophrenia and other psychotic disorders) was used as a reference, and therefore omitted.

* Excluding residents in the capital. 
Early readmissions ( $<7$ days after discharge) were three times less frequent than late readmissions, and this difference is likely to involve distinct mechanisms. Early readmissions are possibly more intimately related to the quality of discharge itself. There is no specific protocol to support discharge decision-making, giving room to a subjective evaluation of stability. Still, every discharge in the two facilities assessed is preceded by a thorough discussion by the multidisciplinary team, which favors a balanced, moderated decision. In both HGV and IRS, discharge is normally tied to the existence of a warranted post-discharge consultation. However, there is no counter-reference systematic mechanism to verify its actual occurrence. Also, cases of transfer to other facilities (i.e., for evaluation and stabilization of a medical comorbidity) could be recorded as discharges followed by short-term readmissions. This happens due to a bureaucratic need, as one same patient cannot simultaneously occupy two beds in different hospitals. Finally, hospital evasions and discharges on request could also result in rapid rehospitalizations, since the sufficient clinical conditions for outpatient treatment were not met.

The availability of outpatient services and mental health professionals in the catchment area/city of origin was associated, in specific ways, with risk of readmission. Only number of basic health units and of psychiatrists (per 100,000 population) proved protective against new readmissions. Surprisingly, the number of CAPS and psychologists per 100,000 population showed an association with shorter intervals to readmission.

Zhang et al. ${ }^{19}$ conducted a study with a similar statistical approach in the metropolitan area of Melbourne, Australia. Regarding outpatient postdischarge treatment, they found that a more assertive and proactive community treatment approach reduced the risk of readmission. Another study conducted in Bogotá, Colombia, found no association between the availability of a psychosocial support network and hospital readmissions; however, the authors suggested that this variable should be disaggregated into its various components for more reliable results. ${ }^{20}$ It must be emphasized that, to our knowledge, no study has thoroughly assessed the impacts of the availability of outpatient resources on psychiatric readmissions. A research conducted in Campo Grande, state of Mato Grosso do Sul, Brazil, showed that only $3 \%$ of discharged patients with schizophrenia reported attending other outpatient mental health services, even though "substitutive services" were available. ${ }^{27}$ Thus, access barriers and non-adherence could be major reasons for failure in stabilizing the patient in the community after a psychiatric hospitalization. Another possibility is that the decision to discharge patients living in areas where CAPS are available could be prematurely taken on the false expectation that CAPS/psychologists would assure protection against readmission. One may also hypothesize that, in a context of chronically repressed mental health demands, the availability of CAPS would function as a gateway for the mental healthcare system. Thus, specific cases with features of extreme severity or difficult out-of-hospital management (i.e., psychotic exacerbations) would require referral to intensive hospital care. This could explain the negative effect of CAPS on readmission risks. If so, this would also suggest that CAPS and psychiatric hospitals coexist in a complementary way, rather than following the usually advocated logic of "substitutive services."

It is unlikely that there is a causal relationship between the availability of psychologists and readmissions. This finding could be the result of a moderate correlation between this variable and the number of CAPS $(r=0.63$; $\mathrm{p}<0.001$ ), or a reverse causal association (more psychologists available where the severe patients are concentrated). However, it is important to emphasize that the expected protective effect was not shown. Even though multidisciplinary care is one of the pillars of modern mental healthcare, ${ }^{28}$ medical attention assumes a relatively higher rank over other approaches for preventing relapse in extremely severe cases that require hospitalization and readmission. That could explain why the availability of psychiatrists, but not of psychologists, reduced readmission risks in the present study.

Another finding that deserves discussion is the protective effect of the availability of basic health units on early, medium-term, and late readmissions. In Belo Horizonte, basic health units were reorganized in the context of the family health program. The capital had a coverage that reached $67-77 \%$ between 2005 and 2011. ${ }^{29}$ Health agents, a nursing team, and a general medical practitioner compose family health teams, who very closely monitor the assigned population. Low-complexity psychiatric cases are a responsibility of those teams, whereas more complex or severe cases are referred for specialized care. However, it is not uncommon that, in the absence of a psychiatrist for referral, the general practitioner be compelled to also manage those more complex cases. By doing so, the continuity of prescriptions is ensured. Also, the structure of care and prevention that basic health units provide probably favors timely interventions, helping to avoid a full relapse.

Belo Horizonte and its metropolitan region display a very particularcombination wherea well-developed public adult outpatient care structure coexists with two public 
psychiatric hospitals. This allowed for a comprehensive observation and analysis of the dynamics of the mental healthcare system in the area. In this open context, it is interesting to observe that readmission rates remained stable after the implementation of the outpatient mental healthcare structure. Again, this indicates that psychiatric hospitals preserve their role in the mental healthcare network, possibly in a complementary way, particularly for the most severe crises that are very difficult to retain in the community.

Some patient characteristics also influenced readmission risks. Being a male was associated to early readmissions. This result opposes to some $20,26,30$ and corroborates other studies. ${ }^{31,32}$ Age was a protective factor, as younger patients had shorter intervals to readmission. A higher risk of readmission has been previously described for young psychiatric patients. ${ }^{21,31,32}$ It is possible that this association is mediated by higher levels of impulsivity and aggression in the youngest, and that those features could influence the decision favoring inpatient treatment.

Psychiatric diagnosis was an independent determinant of risk of readmission. Overall, higher risks of readmission involved substance abuse/dependencerelated disorders, followed by the group of psychotic disorders. These findings support the hypothesis that mental disorders that are more severe, or for which therapeutic results are less favorable, are the ones that require inpatient treatment more intensively.

The fact that one of the two hospitals studied presented consistently higher readmission rates could reflect peculiarities of treatment practices, but also features of the respective outpatient network of reference. In fact, IRS had a higher proportion of patients with substance abuse/dependence disorders than HGV (41 vs. 32\%; $\mathrm{p}<0.001)$ and a lower proportion of patients with neurotic disorders ( 1 vs. $4 \%$; $p<0.001$ ) within this sample, and this may have influenced readmission risks partially. Also, IRS had longer lengths of stay than HGV (median: 12 vs. 5 days; $p<0.001)$. In the total sample, longer lengths of stay determined lower risks of early readmissions and higher risks of late readmissions, and the observed differences in readmission rates between the hospitals were consistent with this pattern. So, the diagnostic profile of the patients and the duration of admissions may have mediated the difference between those two facilities regarding readmission risks. However, the effect of "hospital" was independent from diagnosis and length of stay, and therefore that could not fully explain the observed differences on readmission risks. The duration of admissions, in turn, may reflect the severity of the cases. In that sense, it would be reasonable to suppose that longer admissions would prevent an early rehospitalization (as a result of the quality of discharge, i.e., the patient being more stabilized), but not a late readmission (more connected to the severity of the mental disorder itself).

The present study has several limitations. The quality of secondary data is a crucial factor, considering that collection was retrospective. However, both hospitals used a dedicated database to record information on admissions. When checking for inconsistencies in the databank, rare occurrences of incorrect dates were found, and those observations were discarded. Moreover, the selected timeframe did not allow to determine whether the index admission was the first one for a given patient. For the same reason, we did not retrieve information regarding the number of past admissions before 2005 . We also had no access to possible readmissions to other hospitals, even though there were no other public psychiatric hospitals in the metropolitan region of Belo Horizonte. Thus, only readmissions to general hospitals and those taking place in other parts of the state of Minas Gerais could have remained undetected - probably a very reduced proportion of cases.

\section{Conclusions}

Psychiatric readmission was a frequent phenomenon, comprising over $30 \%$ of all admissions in the two public hospitals studied. Readmission risks were higher in male and young patients diagnosed with substance abuse/dependence-related or psychotic disorders. The high risk profile corresponds to the more severe cases, possibly the most difficult to retain in the community after discharge.

Greater availability of psychiatrists and of basic health units for outpatient care in the catchment area/city of residence were protective factors against readmissions. However, the availability of CAPS and of psychologists did not show any protective effect. These results indicate that the psychiatric hospital effectively integrates the mental healthcare network, complementary to the existing outpatient facilities. Mental healthcare policies should regard those findings in order to produce more effective strategies to provide a fully comprehensive care, considering the whole range of severity of psychiatric disorders.

\section{Acknowledgements}

This research was supported by a grant from Conselho Nacional de Desenvolvimento Científico e Tecnológico (CNPq; grant 470612/2012-6). Isabela Pinto Braga 
received a grant (Bolsa de Iniciação Científica) from Fundação de Amparo à Pesquisa do estado de Minas Gerais (FAPEMIG).

\section{Disclosure}

No conflicts of interest declared concerning the publication of this article.

\section{References}

1. Castro SA, Furegato ARF, Santos JLF. Características sociodemográficas e clínicas em reinternações psiquiátricas. Rev Lat Am Enfermagem. 2010;18:800-8.

2. Dixon $M$, Robertson $E$, George $M$, Oyebode F. Risk factors for acute psychiatric readmission. Psychiatr Bull. 1997;21:600-3.

3. Lin $\mathrm{CH}$, Chen MC, Chou LS, Lin CH, Chen CC, Lane HY. Time to rehospitalization in patients with major depression vs. those with schizophrenia or bipolar I disorder in a public psychiatric hospital. Psychiatry Res. 2010;180:74-9.

4. Zhow $\mathrm{Y}$, Rosenheck RA, Mohamed $\mathrm{S}$, Fan $\mathrm{N}$, Ning $\mathrm{Y}$, $\mathrm{He} \mathrm{H}$. Retrospective assessment of factors associated with readmission in a large psychiatric hospital in Guangzhou, China. Shangai Arch Psychiatry. 2014;26:138-48.

5. Moss J, Li A, Tobin J, Weinstein I, Harimoto T, Lanctôt K. Predictors of readmission to a psychiatry inpatient unit. Compr Psychiatry. 2014;55:426-30.

6. Rieke K, McGeary C, Schmid KK, Watanabe-Galloway S. Risk factors for inpatient psychiatric readmission: are there gender differences? Community Ment Health J. 2016;52:675-82.

7. Parente CJS, Mendes LPF, Souza CNS, Silva DKM, Silva JC, Parente ACBV, et al. O fenômeno de revolving door em hospitais psiquiátricos de uma capital do nordeste brasileiro. REME Rev Min Enferm. 2007;11:381-6.

8. Loch AA. Stigma and higher rates of psychiatric re-hospitalization: São Paulo public mental health system. Rev Bras Psiquiatr. 2012;34:185-92.

9. Mgutshini T. Risk factors for psychiatric re-hospitalization: An exploration. Int J Ment Health Nurs. 2010;19:257-67.

10. Kensagara D, Englander $H$, Salanitro A, Kagen D, Theobald C, Freeman $M$, et al. Risk prediction models for hospital readmission. JAMA. 2011;36:1688-98.

11. Borges FK, Soliman F, Pires DO, Seligman R. Reinternação hospitalar precoce: avaliação de um indicador de qualidade assistencial. Rev HCPA. 2008;28:147-52.

12. Tenório F. A reforma psiquiátrica brasileira, da década de 1980 aos dias atuais: histórias e conceitos. Hist Cienc Saude Manguinhos. 2002;9:25-59.

13. Amarante P. Novos sujeitos, novos direitos: o debate em torno da reforma psiquiátrica. Cad Saude Publica. 1995;11:491-4.

14. Gonçalves AM. A reforma psiquiátrica no Brasil: contextualização e reflexos sobre o cuidado com o doente mental na família. Rev Lat Am Enfermagem. 2001;9:48-55.

15. Brasil, Casa Civil. Lei no 10.216, de 6 de abril de 2001. Dispõe sobre a proteção e os direitos das pessoas portadoras de transtornos mentais e redireciona o modelo assistencial em saúde mental [Internet]. [cited 2017 Jan 27]. http://www.planalto.gov. br/ccivil 03/leis/leis 2001/l10216.htm

16. Brasil, Ministério da Saúde. Reforma psiquiátrica e política de saúde mental no Brasil. In: Conferência Regional de Reforma dos Serviços de Saúde Mental: 15 anos depois de Caracas. Brasília: OPAS; 2005.

17. Hamilton JE, Rhoads H, Galvez J, Allen M, Green C, Aller M, et al. Factors differentially associated with early readmission at a university teaching psychiatric hospital. J Eval Clin Pract. $2015 ; 21: 572-8$

18. Lorine K, Goenjian H, Kim S, Steinberg AM, Schmidt K, Goenjian AK. Risk factors associated with psychiatric readmission. J Nerv Ment Dis. 2015;203:425-30.

19. Zhang J, Harvey C, Andrew C. Factors associated with length of stay and the risk of readmission in an acute psychiatric inpatient facility: a retrospective study. Aust N Z J Psychiatry. 2011;45:57885.

20. Sánchez R, Jaramillo E, Herazo MI. Factores asociados a rehospitalización temprana em psiquiatría. Biomédica (Bogota). 2013:33:276-82.

21. Rosca P, Bauer A, Grinshpoon A, Khawaled R, Mester R, Ponizovsky AM. Rehospitalizations among psychiatric patients whose first admission was involuntary: a 10-year follow-up. Isr J Psychiatry Relat Sci. 2006;43:57-64.

22. Moss J, Li A, Tobin J, Weinstein IS, Harimoto T, Lanctôt KL. Predictors of readmission to a psychiatry inpatient unit. Compr Psychiatry. 2014;55:426-30.

23. Mgutshini T. Risk factors for psychiatric re-hospitalization: an exploration. Int J Ment Health Nurs. 2010;19:257-67.

24. Byrne SL, Hooke GR, Page AC. Readmission: a useful indicator of the quality of inpatient psychiatric care. J Affect Disord. 2010;126:206-13.

25. Mahendran R, Mythily, Chong SA, Chan YH. Brief communication: factors affecting rehospitalisation in psychiatric patients in Singapore. Int J Soc Psychiatry. 2005;51:101-5.

26. Korkeila JA, Lehtinen V, Tuori T, Helenius H. Frequently hospitalised psychiatric patients: a study of predictive factors. Soc Psychiatry Psychiatr Epidemiol. 1998;33:528-34.

27. Pinheiro TLS, Cazola LHO, Sales CM, Andrade ARO. Fatores relacionados com as reinternações de portadores de esquizofrenia. Cogitare Enferm. 2010;15:302-7.

28. Brasil, Ministério da Saúde. Legislação em saúde mental: 19902004. Brasília: Ministério da Saúde; 2004.

29. Brasil, Ministério da Saúde. Histórico de cobertura da Saúde da Família [Internet]. [cited 2017 Jan 27]. http://dab.saude.gov.br/ portaldab/historico_cobertura_sf.php

30. Valevski A, Olfson M Abraham W, Shiloh R. Risk of readmission in compulsorily and voluntarily admitted patients. Soc Psychiatry Psychiatr Epidemiol. 2007;42:916-22.

31. Bernardo AC, Forchuk C. Factors associated with readmission to a psychiatric facility. Psychiatr Serv. 2001;52:1100-02.

32. Sanguineti VR, Samuel SE, Schwartz SL, Robeson MR. Retrospective study of 2,200 involuntary psychiatric admissions and readmissions. Am J Psychiatry. 1996;153:392-6.

\section{Correspondence:}

Fernando Madalena Volpe

Fundação Hospitalar do Estado de Minas Gerais

Alameda Alvaro Celso, 100

30150-260 - Belo Horizonte, MG - Brazil

Tel: +55 (31) 32611161

E-mail: fernando.madalena.volpe@gmail.com 